\title{
Adapting Quantitative Survey \\ Procedures: The Price for Assessing \\ Vulnerability? Lessons \\ from a Large-Scale Survey on Aging \\ and Migration in Switzerland
}

\author{
Laure Kaeser
}

\section{Capturing Vulnerable Populations: A Dilemma for Large-Scale Quantitative Surveys}

This chapter aims at understanding the issues of capturing vulnerable populations in large-scale quantitative surveys. We limit ourselves to a specific group, elderly migrants, who nevertheless illustrate a global challenge. Surveying vulnerability requires being able to gain access to vulnerable individuals or groups. Vulnerability is defined as: "A lack of resources, which in a specific context, places individuals or groups at a major risk of experiencing (1) negative consequences related to sources of stress; (2) the inability to cope effectively with stressors; and (3) the inability to recover from the stressor or to take advantage of opportunities by a given deadline" (Spini et al. 2013).

These populations are often hard to reach for surveyors; according to the definition, it is primarily a lack of resources, within a specific context, that places certain groups at a major risk of not being represented by large-scale surveys. Such a deficiency translates into problems of availability (being homeless or away from home during data collection period), absence of identification with the survey goals and uses (refusing to participate, misunderstanding the survey questions, refusing to be contacted, etc.), inability to answer to survey questions (not speaking the local language, not reading properly, mental handicap, etc.) or special group features such as ethnic or religious minority groups, or drug users (Schiltz 2005; Riandey and Quaglia 2009; Marpsat and Razafindratsima 2010).

L. Kaeser ( $\square)$

NCCR LIVES, IP 213, Geneva, Switzerland

Centre for the Interdisciplinary Study of Gerontology and Vulnerability,

University of Geneva, Geneva, Switzerland

e-mail: laurekaeser@gmail.com 
Thus, the dilemma in survey construction arises when a target vulnerable population to be analyzed cannot be reached using standard survey design. Indeed, adapting standard procedures may help to improve access to the targeted vulnerable population; however, these changes may lead to inaccurate comparisons with other population subgroups.

To discuss this dilemma, this chapter deals with the data collection process of the large-scale survey on aging Vivre/Leben/Vivere: Old Age Democratization? Progress and Inequalities in Switzerland (VLV). VLV aims at analyzing life and health conditions and trajectories of the population aged 65 and over living in the Swiss Confederation. VLV also includes a focus on ageing populations with a migrant background. Researchers at the Center for the Interdisciplinary Study of Gerontology and Vulnerability in Geneva were responsible for designing the study and analyzing the data. They were also responsible for conducting the data collection, which took place in 2011 and 2012.

VLV is a quantitative survey that in many ways reflects the above-mentioned methodological challenges. It is based on two samples: the main sample of people over 65 years old living in five cantons, and an oversample of elderly migrants living in the cantons of Basel and Geneva (see the Sect. 3 for more details on the research design). The VLV research team strictly defined contact and interviewing procedures and standardized the data collection for all selected sample units. Since the research objectives included studying elderly people with a migrant background, ${ }^{1}$ it was initially decided to use the same research design for them as for the main sample precisely to avoid a priori differences. Nevertheless, elements of vulnerability made them hard to reach for reasons explicitly explained below. To avoid this potential failure, the team decided to adapt some of the standard procedures, but this was not without giving up some benefits of standardization. This chapter tells the story of VLV's successes and failures, with the aim of highlighting the tension between scientific requirements and realities on the ground in the context of surveying vulnerability.

To do so, this chapter explains why the case of elderly migrants is relevant to discussing the dilemma of capturing vulnerability within large-scale surveys. Then it questions the need to adjust standard procedures of a quantitative survey, and the impact of doing so, to access elderly migrants. Finally, we show the need for a constant dialogue around the scientific requirements and the realities of fieldwork in order to avoid an under-representation of vulnerable groups in surveys, which can also be viewed as a form of discrimination. For example, Elcheroth and his colleagues have argued that, "Systematic bias in survey response also intrigues because it appears to betray a democratic ideal that is frequently projected onto surveys: one person, one voice. The substantive concern about processes that

\footnotetext{
${ }^{1}$ Immigrant is defined as an individual born in another country than the one he/she lives in and who has crossed a border (or several borders) since his/her birth. He/she may be citizen of his/her birth country or another country, in particular of his/her country of residence (Definition of the French National Institute of Demographic Study).
} 
produce social exclusion, and that reproduce it in particular by way of exclusion from social surveys, goes hand-in-hand with the pragmatic concern to enhance the representativeness of surveys, not least in order to break societal and scientific cycles that render certain minorities invisible to the public eye (and leave the public indifferent to their fate)" (Elcheroth et al. 2011: 4).

\section{Surveying Elderly Migrants as an Illustration of Surveying Vulnerability}

Many studies on survey methodology underline the difficulties in obtaining a representative sample of the target population. Results may be inferred to the whole (sub)population thanks to sampling methods, which determine the quality of the sample representativeness (Tabutin 2006; Gerville-Réache et al. 2011). Nevertheless, even if the sampling method promises representativeness, some subpopulations are hard to reach for availability, access, or monitoring reasons. This may lead to differences between the original sample and the size and profile of the responding sample (Groves and Couper 1998; Elcheroth et al. 2011).

Groves and Couper (1998) identify several reasons explaining participation in surveys: individual characteristics such as social and/or psychological components (including attitudes, norms and values); demographic variables (age, marital status, household structure, education, income, place of residence); and from a heuristic perspective, features of the research design (data collection mode, number of contact attempts, period of data collection); the interviewers' characteristics (sex, age, experience); and interactions between interviewers and respondents. VLV decided to deal with the elderly migrants in almost the same way as the other elderly sample members. Because of their life course, however, elderly migrants differ from the overall population in a number of specific ways. Their particular characteristics may interfere with their participation in the survey. These points are detailed below.

In Switzerland, most elders of foreign origin arrived in the second half of the twentieth century. They mainly came from Italy in the 1950s, from Spain in the 1960s, and from Portugal and former Yugoslavia in the 1980s and early 1990s (Piguet 2004). After World War II, the main goal of Swiss migratory policy was to get temporary workers responding to the needs of a growing economy without competing with Swiss natives. Immigrants experienced severe legal restrictions (including the interdiction of family reunification, seasonal status) and a lack of integration policies until the early 1990s. A part of the Swiss population also openly expressed hostility against immigrants during the campaign for the socalled Schwarzenbach initiatives ${ }^{2}$ against "foreign overpopulation." In this context, painful professional and health trajectories have been part of individual migration

\footnotetext{
${ }^{2}$ Schwarzenbach's initiatives (originating from the name of the initiator, representative of the "Action nationaliste," a conservative political party) were initiatives against the "foreign over-
} 
stories. As a consequence, elderly migrants are overrepresented among the most disadvantaged groups of the retired population in Switzerland (Bolzman et al. 2004).

Small-scale studies in the cities/cantons of Geneva and Basel (Bolzman et al. 2001, 2004) have highlighted special features of the living conditions of elderly people coming from abroad compared to the overall population. Most of them worked in low-skilled jobs (e.g. construction, industry, cleaning). Their income is on average lower than that for Swiss natives because of an earlier retirement age (explained by bad health status due to the demanding nature of the work and higher risk of unemployment) and/or a shorter contribution period to the retirement funds (e.g. due to carrying out professional activity in two or more countries). Those with the worst health status were active in the construction sector; half of whom receive benefits from disability insurance (Bolzman et al. 2004).

Nowadays, elderly migrants have either chosen to, or must, spend the last stage of their lives in their host country. They are on average younger than the Swiss population but the share of elderly migrants within the total population aged 65 and over is increasing steadily. ${ }^{3}$ People originating from Italy, Germany, France, Austria, and Spain are the most numerous. But the proportion of each nationality in relation to the total foreign population varies over time. This evolution reflects the various migration movements during the last century. Italians constitute the most important group among elderly migrants, representing around $40 \%$ of the foreign population aged 65 and over. This share has not varied much over time, while by contrast, other nationalities are constantly on the rise, especially those from southern Europe, including more recent migration flows such as those originating in Portugal or Turkey. In contrast, there has been a large decrease in the number of Northern Europeans in the foreign aged population of Switzerland.

When surveying these groups, including those coming from the south of the continent, numerous obstacles induced by their life trajectories and current living conditions may engender their underrepresentation in the responding sample. Scientific literature reveals that there are various barriers that make people with a migrant background hard to reach by standard survey fieldwork procedures. Not speaking the survey language is one factor. But having living conditions that make someone uneasily reachable by standard procedures or having a system of beliefs and values that make the questions not understandable constitute major difficulties as well (Feskens et al. 2006; Lipps et al. 2011; Elcheroth et al. 2011; Laganà et al. 2011). Moreover, analysis of reasons for inclusion and exclusion of national minority groups from Swiss large-scale surveys confirms the relation between nonresponse

population" submitted twice to the vote of the Swiss population in the 1970s. Finally refused, they deeply impacted the foreign populations living in Switzerland at that time.

${ }^{3}$ In 1995, the resident foreign population aged 65 and over represented $6.0 \%$ of the total resident population of that age. This share grew to $10.5 \%$ by 2010 . This increase would be even more striking if people of immigrant origin who became Swiss citizens were taken into account. As for the total resident population 65 and over, there was an increase of $21 \%$ from 1995 to 2010, while the foreign population increased $55 \%$ in the same period of time (Swiss Federal Statistical Office 2012). 
rate and ethno-social affiliations (Lipps et al. 2011; Elcheroth et al. 2011; Laganà et al. 2013). These studies conclude that the underrepresentation of national minorities results in bias even after controlling for socioeconomic status. Though weak for people speaking the same language and from neighboring countries, this problem becomes extreme for people originating from former Yugoslavia, Albania, Turkey, and outside Europe (Elcheroth et al. 2011; Lipps et al. 2011). In the case of VLV and referring to the work of Groves and Couper (1998), elderly migrants' characteristics such as their age, language, overrepresentation in low socioeconomic and health status groups, low level of education and ambivalent position in several cultural contexts may impair their representation within a large-scale survey. However, Elcheroth and his colleagues argue that, "The inclusion/exclusion of minority groups in/from general social surveys might be one of the most challenging and understudied issues in contemporary survey research" (Elcheroth et al. 2011: 1).

It is also important to keep in mind that migration issues represent a challenge for social science surveys precisely because of their socio-political dimension. From a broad perspective, the methodological challenges are underpinned by the necessity for public actors, especially those defining social policies, to get reliable statistics to understand the evolution of social problems and their subsequent needs (Rossini 2013: 92). In the case of VLV, surveying elderly migrants specifically questions the need for public policies to get a more detailed picture of the life conditions, resources, and requests of these growing populations. Thus, surveying migrants also constitutes a challenge for surveys on aging to access a growing population among the most vulnerable retired persons. Various papers published in Switzerland and elsewhere in Europe have stressed the improvement in the living conditions, health status, and well-being of the new cohorts reaching retirement age (Von Dem Knesebeck et al. 2007; Lalive d'Epinay et al. 2000). However, if these findings are well established for elderly persons in general, much less is known about the population of migrant workers who are now retired. In this light, being able to represent elderly migrants within a large-scale survey is a challenge in terms of generating knowledge for the orientation of policies targeted at the aging population.

Including elderly migrants in the general VLV research design implied several adaptations of standard procedures, and these adjustments reflect the dilemma mentioned in the introduction. In summary, the VLV experience of attempting to survey elderly migrants raised the following questions:

- Which were the specific obstacles that prevented elderly migrants from participating in the VLV survey with the standard fieldwork procedures and which elements of vulnerability do these obstacles underline?

- Which adaptations succeeded in overcoming these obstacles and improving the access to elderly migrants?

- If their inclusion in the survey was better in quantitative terms (higher response rate), what was the impact of the adjustments to standard procedures on the data quality? In other words, was the representativeness of the responding sample of elderly migrants affected by the adaptations of the procedures implemented in the middle of the fieldwork? 
Once again, this chapter examines the need to adapt standard survey procedures in order to facilitate the participation of elderly immigrants, who make up an important part of the most vulnerable groups within the aging population. We developed an original methodological framework based on quantitative and qualitative data to empirically address this issue.

\section{A Mixed Method Design for Analyzing VLV's Ability to Survey Elderly Migrants}

Our analyses are based on the VLV field research. Scholars from various disciplinary backgrounds (medicine, psychiatry, psychology, sociology and demography) designed the VLV study and delegated the data collection to researchers from the Center for Interdisciplinary Gerontology and the study of vulnerabilities (hereafter referred to as "the VLV team"). The survey was conducted in 2011 and 2012 in five Swiss cantons: Geneva, Valais (restricted to the Central Valais area), Bern (restricted to the Mittelland, Oberland, and Seeland areas), Basel (including BaselStadt and Basel-Land) and Ticino. In each canton, 20-30 external interviewers were hired to contact the respondents and conduct the interviews, and two to three members of the VLV team managed the interviewers and monitored the fieldwork. The main target sample consisted of 3600 individuals and was randomly selected in the cantonal population records, and stratified by age $(65-69 ; 70-74 ; 75-79 ; 80-84$; $85-89$; 90 and above) and sex, for a total of 720 respondents in each canton, either community dwelling or living in nursing homes. The contact procedure was done either by phone or a visit at home in case of no landline phone. Then, the survey was conducted in two phases. First, the respondents received a self-administered questionnaire and a life-event calendar. Second, an interviewer conducted a face-toface interview with an average duration of $2 \mathrm{~h}$ (Ludwig et al. 2014).

To address the increasing diversity of the elderly population, an important subproject of VLV was set up to investigate the living conditions and the life trajectories of elderly migrants compared to the national population. In addition to the main sample, VLV researchers decided to oversample the migrant population. Oversamples stratified by sex were planned in the cantons of Geneva and Basel based on people aged between 65 and 79, with 120 individuals by nationality. In Geneva, the oversample included natives from Portugal, Spain, and Italy. In Basel, it was originally intended to interview people from Italy and former Yugoslavia. These choices of groups and sites were determined by the distribution of these populations relative to the national population and other ethnic-minority groups.

Nevertheless, obstacles such as a low response rate quickly emerged (see below) and began to compromise the data collection. Therefore, the VLV team decided to adjust some features of the research design with varying success. To identify causes of exclusion of elderly migrants within VLV, we collected and analyzed quantitative and qualitative data. Scholars using qualitative approaches regularly undertake a 
reflective and critical exercise relating to the production of data, especially on issues related to strategies for negotiating and gaining access to carry out fieldwork. Such a critical exercise may also constitute an introduction to data analysis: types of access to the fieldwork and reception of the survey may be indicative of certain characteristics of the target population (Mauger 1991; Bonnet 2008). Moreover, even if they are used less in survey research, qualitative data remain of great interest for understanding what is being examined with survey practices. Indeed, "Ethnographic approaches to interviewer experiences and interviewer respondent interactions should provide a more fine-grained understanding of the micro-process by which certain types of respondents are excluded from survey participation, on the basis of reciprocal expectations, perceptions, and communicative practices" (Elcheroth et al. 2011: 11).

A qualitative approach gives a better understanding of the perception of the survey by elderly migrants. During the fieldwork, it also gave suggestions to researchers about how to adapt the procedures to improve the response rate and survey practices. Three bodies of text were analyzed. First, researchers in charge of the data collection kept logbooks of oral reports from interviewers responsible for the oversamples. The analysis of these field stories complemented data from the VLV fieldwork monitoring by giving interpretations of the reasons for non-response (refusal and non-contact). Second, a content analysis of strategic discussions within the VLV team examined the effects of the procedures for elderly migrants compared to the rest of the sample. Finally, a focus group with the interviewers in charge of the oversamples was created to better understand the perception of the VLV approach procedures and the way to conduct interviewing among these populations.

On the quantitative side, access to the research field was analyzed with respect to effects on the representativeness of the population covered by the study (Groves 2006; Marpsat and Razafindratsima 2010). Thus, we analyzed refusal, nonresponse, and contact rates of elderly migrants compared to the main sample. The monitoring of VLV, which collected results on contact attempts, made these classical analyses in survey methodology possible (Groves and Couper 1998). We also conducted statistical tests on the final sample to verify if the adjustments of procedures introduced biases. Thus, combining qualitative and quantitative approaches helps to shed light on VLV data production and its adaptation strategies.

\section{Varying Effects of Adjusting Procedures to Survey Elderly Migrants}

It is worth remembering that the VLV team made the initial decision to not construct a priori differences between elderly migrants and the rest of the sample by applying the same contact and interviewing procedures to both. This is a crucial starting point since this choice resulted in underestimating risks related to equal treatment of these populations. Nevertheless, it was not a completely strict approach. 
Four subsidiary measures were implemented from the start: first, oversampling people originating from Italy, Spain, Portugal and former Yugoslavia; second, translations of survey materials; third, recruitment of bilingual interviewers; and fourth, promotion of the survey in migrant communities. These decisions were built upon the experiences of the previously mentioned surveys of elderly migrants in Switzerland for which the representativeness of the final samples of respondents had been ensured. This fieldwork highlighted two elements of vulnerability faced by aging immigrants: the lack of language proficiency and the distrust of the administrative aspects of the survey. The four measures taken dealt with these problems and were assumed to not interfere with the initial objective, which was to apply the same research design to native and non-native elderly persons. This approach was designed to facilitate access to fieldwork and overcome any language barriers. Bilingual interviewers were trained the same way as the other interviewers; the entire material was translated without any modification, and the same contact and interviewing procedures were used. However, these four measures had varying effects, as described in the following.

Since elderly migrants only represent a small part of the elderly population and as it was assumed that they would probably have a lower response rate than the overall main sample, oversamples were planned to make sure that the final sample size would be large enough to permit reliable quantitative analysis. Four oversamples were foreseen, each with 120 respondents. However, in the end, as Table 1 shows, the planned objectives for the oversample were not achieved.

The motivation for translating the survey materials was based on the hypothesis that some elderly migrants would not have been able to understand the questionnaires in French or German. There are several reasons for a lack of language proficiency in these subpopulations (e.g. lack of time, low level of education, demanding jobs, etc.), all of which may create daily obstacles to accessing services for these people. It also may lead to a major risk of under-representation in the survey of people who feel less comfortable speaking, or feel unable to answer questions in the local language. Contact letters, life event calendars, and instructions (see Fig. 1), self-administrated and face-to-face questionnaires were all translated into Portuguese, Spanish, Italian, Albanian, and Serbo-Croatian.

In Geneva, $87 \%$ of the Portuguese respondents in the oversample, $81 \%$ of the Spanish respondents in the oversample, and $90 \%$ of the Italian respondents in the oversample responded in their native language. These results highlight how crucial the translation option is for reaching elderly migrants. High proportions of those

Table 1 Final oversamples obtained by random procedures (planned effectiveness: 120 by nationality and canton)

\begin{tabular}{l|l|l|l|l}
\hline & \multicolumn{2}{|l|}{ Geneva } & Basel \\
\cline { 2 - 5 } & Portugal & Spain & Italy & Former Yugoslavia \\
\hline Random oversamples & 61 & 41 & 46 & 5 \\
\hline
\end{tabular}

Planned effectiveness: 120 by nationality and canton 


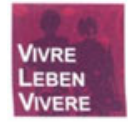
DE GENEVE

VIVERE

\section{Calendario de vida}

\section{EJEMPLO}

La Sra. Claire Dupont tiene 86 años y creció en Evolene. A los 16 anos, se va a trabajar a Zermatt. Ahi conoce a Henri. Se casan dos años más tarde. Después de tener cinco hijos, empieza un trabajo como secretaria. En 1972. se le detecta un cáncer de seno. tiempo de trabajo. Poco después del allecimiento de su esposo, se somete a una cirugia del corazón. Debido a estos acontecimientos, la Sra. Dupont se ve obligada a vender su casa y a en Sion.
9. UNIVERSITE situación que la obliga a disminuir su mudarse. Actualmente vive en un EMS

\begin{tabular}{|c|c|c|c|c|c|c|c|c|}
\hline Año & Edad & Residencia & $\begin{array}{c}\text { Familia I } \\
\text { Pareja }\end{array}$ & Actividad & $\begin{array}{l}\text { Id } \\
\text { Carga }\end{array}$ & Salud & Nacionalidad & Edad \\
\hline 1925 & 0 & EvoleneVs & & & & & Suiza & 0 \\
\hline 1926 & 1 & & & & & & & 1 \\
\hline 1927 & 2 & & Nace herman & & & & & 2 \\
\hline 1928 & 3 & & & & & & & 3 \\
\hline 1929 & 4 & & & & & & & 4 \\
\hline 1930 & 5 & & Nace herman & & & & & 5 \\
\hline 1931 & 6 & & & & & & & 6 \\
\hline 1932 & 7 & & & Escuela obtigs & gaton & ta & & 7 \\
\hline 1933 & 8 & & Nace heman & & & & & 8 \\
\hline 1934 & 9 & & & & & & & 9 \\
\hline 1935 & 10 & & & & & & & 10 \\
\hline 1936 & 11 & & & & & & & 11 \\
\hline 1937 & 12 & & & Escuela para la & aytarea & ardomesticas & & 12 \\
\hline 1938 & 13 & & & & & & & 13 \\
\hline 1939 & 14 & & & Ayuda en la & gran & ya & & 14 \\
\hline 1940 & 15 & & & & & & & 15 \\
\hline 1941 & 16 & Zermatt, VS & & Seriona de la & 2100 & & & 16 \\
\hline 1942 & 17 & & & limpieza & & & & 17 \\
\hline 1943 & 18 & & Conocettenn & & & & & 18 \\
\hline 1944 & 19 & & & & & & & 19 \\
\hline 1945 & 20 & & & & & & & 20 \\
\hline 1946 & 21 & Nendasi $I I$ & Matrimonio & Hogar & 0 & & & 21 \\
\hline 1947 & 22 & & Nace Paul & & & & & 22 \\
\hline 1948 & 23 & & & & & & & 23 \\
\hline 1949 & 24 & & Nace Anne & & & & & 24 \\
\hline 1950 & 25 & & & & & & & 25 \\
\hline 1951 & 26 & & & & & & & 26 \\
\hline 1952 & 27 & & & & & & & 27 \\
\hline 1953 & 28 & & Nace Gabriet & & & & & 28 \\
\hline 1954 & 29 & & Nace Emile & & & & & 29 \\
\hline 1955 & 30 & & & & & & & 30 \\
\hline 1956 & 31 & & & & & & & 31 \\
\hline 1957 & 32 & & & & & & & 32 \\
\hline 1958 & 33 & & & 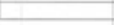 & & & & 33 \\
\hline 1959 & 34 & & Nace Yonne & & & & & 34 \\
\hline 1960 & 35 & & & 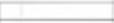 & & & & 35 \\
\hline 1961 & 36 & & & 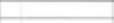 & & & & 36 \\
\hline 1962 & 37 & & & 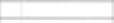 & & & & 37 \\
\hline 1963 & 38 & & & 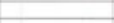 & & & & 38 \\
\hline 1964 & 39 & & & & & & & 39 \\
\hline 1965 & 40 & & & Secretaria & 50 & & & 40 \\
\hline 1966 & 41 & & & & & & & 41 \\
\hline 1967 & 42 & & & & & & & 42 \\
\hline 1968 & 43 & & & - & & & & 43 \\
\hline 1969 & 44 & & & & & & & 44 \\
\hline 1970 & 45 & & Fallecimiento & opadre & & & & 45 \\
\hline 1971 & 46 & & & & & & & 46 \\
\hline 1972 & 47 & & & $x_{2}$ & 30 & Cancer des & eno & 47 \\
\hline 1973 & 48 & & Fallecimiento & onegra & & & & 48 \\
\hline 1974 & 49 & & & 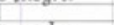 & & & & 49 \\
\hline 1975 & 50 & & Fallecimiento & omadre & & & & 50 \\
\hline 1976 & 51 & & & & 50 & & & 51 \\
\hline 1977 & 52 & & & & & & & 52 \\
\hline 1978 & 53 & & Abuela & & & & & 53 \\
\hline 1979 & 54 & & & & & & & 54 \\
\hline 1980 & 55 & & & & & & & 55 \\
\hline 1981 & 56 & & & & & & & 56 \\
\hline 1982 & 57 & & & & & & & 57 \\
\hline 1983 & 58 & & & 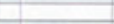 & & & & 58 \\
\hline 1984 & 59 & & & & & & & 59 \\
\hline 1985 & 60 & & & & & & & 60 \\
\hline 1986 & 61 & & & & & & & 61 \\
\hline 1987 & 62 & & & fublación & & & & 62 \\
\hline 1988 & 63 & & & & & & & 63 \\
\hline 1989 & 64 & & & & & & & 64 \\
\hline 1990 & 65 & & & & & Accidente de & equto & 65 \\
\hline 1991 & 66 & & & & & & & 66 \\
\hline 1992 & 67 & & & & & & & 67 \\
\hline 1993 & 68 & & Fallecimiento & ohermano & & & & 68 \\
\hline 1994 & 69 & & & & & & & 69 \\
\hline 1995 & 70 & & & & & & & 70 \\
\hline 1996 & 71 & & & & & & & 71 \\
\hline 1997 & 72 & & & & & & & 72 \\
\hline 1998 & 73 & & & & & & & 73 \\
\hline 1999 & 74 & & Fallecimiento & oftenri & & Cirugia del & corazón & 74 \\
\hline 2000 & 75 & Sion & & & & & & 75 \\
\hline 2001 & 76 & & & & & & & 76 \\
\hline 2002 & 77 & & & & & & & 77 \\
\hline 2003 & 78 & & & & & & & 78 \\
\hline 2004 & 79 & & & & & & & 79 \\
\hline 2005 & 80 & & conoce Stefar & ine & & & & 80 \\
\hline 2006 & 81 & & & & & & & 81 \\
\hline 2007 & 82 & & & & & & & 82 \\
\hline 2008 & 83 & & & & & & & 83 \\
\hline 2009 & 84 & EMS, Sion, VS & & & & Fractura de & cuellodel & 84 \\
\hline 2010 & 85 & & & & & fémur & & 85 \\
\hline 2011 & 86 & & & & & & & 86 \\
\hline Año & Edad & & & & Carga & & & Edad \\
\hline & & Residencia & 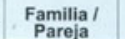 & Actividad & & Salud & Nacionalidad & \\
\hline
\end{tabular}

Fig. 1 Example of the VLV life event calendar translated into Spanish 
who chose to answer in their mother tongue included people who would have been able to answer in the local language but who felt more comfortable and confident when answering in their native language.

Nevertheless, this measure also has some side effects. For scientific translations, two professional translators should translate the survey material with constant dialogue with researchers (Harckness 2003). There was at least one member of the VLV team who was a native speaker in Portuguese, Italian and Spanish. But this was not the case for Albanian and Serbo-Croatian, resulting in some uncertainty and insecurity in trusting the validity of the translations. There was confusion between Serbian and Croatian and two translations had to be done without being reviewed by a researcher from the VLV team. Moreover, translations into Albanian, Serbian, and Croatian were incorrectly evaluated by the interviewers in charge of the Yugoslavian oversamples leading to "on-the-fly" corrections by the interviewers. To conclude, such translation procedures consume time and money. Results may also imply negotiating within the team on the priorities to give to translations among other survey needs, considering human and financial resources. This may explain why many surveys do not translate their questionnaires and run the risk of not reaching immigrants who did not get the opportunity to master the local language enough to understand relatively complex questionnaires.

For contact and interviewing procedures in native and local languages, bilingual interviewers were hired. The same interviewers conducted the initial contact, follow-up of the respondent files, and face-to-face interviews. The VLV team in Basel and Geneva recruited people with graduate degrees. Preference was given to second-generation immigrants from the same country as the target populations but this was kept as an option. Language and interviewing competences were prioritized and we did not pay much attention to cultural proximity. As an example, the first wave of Geneva interviewers included first-generation migrants from Latin America. However, those Latin American collaborators reported signs of rejection from Spanish and Portuguese elderly. These interviewers complained about being judged as less legitimate, or less well-integrated newcomers by the respondents, i.e. the former generations of immigrants. Some respondents did not understand, and sometimes did not accept, being interviewed by people from Latin America. Interviewers from the second generation also spoke about some signs of social distance, of a generational gap; "You cannot understand what we went through" was the kind of sentence often heard during contact or interviewing. Finally, recruiting interviewers with a university degree and being a member of the Albanian and Serbo-Croatian communities in Basel proved to be difficult. For the Serbo-Croatian interviews, this difficulty was greater during the contact procedure if the respondent was not from the same community of origin because of resentments from the war in ex-Yugoslavia in the 1990s. This led to a high degree of mistrust toward the interviewers and, most of the time, to refusal to participate as well.

The last measure mentioned was to promote the study among migrant communities. This was designed to reduce distrust. Letters were sent to immigrant associations. Information also circulated among mass media (radio and newspapers), 
churches, grocery stores, bars, where Portuguese, Spanish, or Italians often went. The impact of such a promotion is hard to measure:

It's hard to give an opinion of the efficiency of the promotion. Honestly, I'm not sure it was really effective. Out of all the people I interviewed, I had two people who said they had heard of us. Once at the church and once at the Casa Benefica. (148, Portuguese interviewer).

But some were reassured that the survey was serious:

I got some feedback from the respondents. They had seen the poster at the Spanish consulate and also at the church .... People talking about that said that it reassured them, that it was not fraudulent [approval of other interviewers]. That it was not a rip-off. (159, Spanish interviewer)

These measures confirm the aforementioned elements of vulnerability: a lack of proficiency in local language and distrust toward survey features provide evidence of social distance between the VLV research design and the target populations. Despite measures to overcome these obstacles, the response rate remained low and other, unexpected obstacles started to appear.

\section{VLV Research Design Confronted with Realities on the Ground}

Portuguese and Spanish oversamples in Geneva were the first two projects launched. Despite the measures initially taken, it appeared that elderly migrants were harder to reach than expected because of various reasons explained below. After a few weeks, the response rate remained low; after 6 weeks, it was only $2 \%$ for Portuguese and $8 \%$ for Spanish. The Italian oversample was launched in Basel a few weeks later and experienced the same difficulties in motivating people to participate. The former Yugoslavian oversample launched at the same time as the Italian one was doing worse; after experiencing many difficulties with translations and interviewer recruitment, the VLV team was confronted with a quasi-systematic refusal from former Yugoslavian elders.

The low response rate of elderly immigrants was due to higher non-contact rate and a higher refusal rate than for the main sample. We calculated the final response, refusal, and contact rates according to the standards of the American Association for Public Opinion Research. ${ }^{4}$ The response rate refers to the number of people who wholly or partially completed the questionnaires. It was $36 \%$ for the VLV main

\footnotetext{
${ }^{4}$ Standard definitions of the American Association for Public Opinion Research (2010):

- Response rate $=(\mathrm{I}+\mathrm{P}) /(\mathrm{I}+\mathrm{P})+(\mathrm{R}+\mathrm{NC}+\mathrm{O})+(\mathrm{UH}+\mathrm{UO})$

- Refusal rate $=\mathrm{R} /((\mathrm{I}+\mathrm{P})+(\mathrm{R}+\mathrm{NC}+\mathrm{O})+\mathrm{UH}+\mathrm{UO}))$

- Contact rate $=(\mathrm{I}+\mathrm{P})+\mathrm{R}+\mathrm{O} /(\mathrm{I}+\mathrm{P})+\mathrm{R}+\mathrm{O}+\mathrm{NC}+(\mathrm{UH}+\mathrm{UO})$

$\mathrm{I}=$ completed interview; $\mathrm{P}=$ partial interview; $\mathrm{R}=$ refusal and break-off; $\mathrm{NC}=$ Non-contact; $\mathrm{O}=$ Other; $\mathrm{UH}=$ Unknown Household; $\mathrm{UO}=$ Unknown other.

For additional information, please refer to the following Web site:

http://www.aapor.org/Standard_Definitions2/4232.htm
} 
Table 2 Response, refusal, and contact rates by nationality

\begin{tabular}{l|l|l|l}
\hline & Italians & Portuguese & Spanish \\
\hline Response rate & 0.15 & 0.22 & 0.18 \\
\hline Refusal rate & 0.66 & 0.37 & 0.59 \\
\hline Contact rate & 0.81 & 0.59 & 0.76 \\
\hline Oversample—Geneva—Individuals reached by \\
snowball procedures not included
\end{tabular}

sample in Geneva (Guichard et al. 2012), illustrating the difficulties of running a survey in Switzerland, a country where low rates of participation in surveys are increasingly commonplace (see the chapter of Oris et al. in this volume). The rate was even lower for the oversample populations. It was particularly low for the Spanish and Portuguese (see Table 2). Spanish and Italians tended to be easier to reach but had a higher refusal rate, whereas Portuguese were less reachable but more inclined to complete the questionnaires.

The contact rate refers to the proportion of all cases contacted including those who refused to participate. Compared to the Italians and Spanish, the Portuguese were much harder to contact. Having or not having a landline phone may explain this: more than $37 \%$ of the Portuguese oversample did not have a landline phone, compared to $23 \%$ for the Italians and Spanish. As a reminder, in the case of no landline phone, the instruction was to do a visit at home. The success rate for such a procedure was low in Geneva for the main sample. For the oversamples, the visit procedure turned out to be unfruitful because elderly migrants are generally away from home for several weeks due to travelling back-and-forth between their home country and Switzerland. This procedure was gradually given up because it was time and money consuming. According to the reports of the Portuguese interviewers and members of the community, many Portuguese migrants choose to go back and forth between Switzerland and Portugal. These people spend only a few weeks of the year in Switzerland, which makes them hard to reach, whereas this way of living might be less financially advantageous for the Italians and Spanish.

Once a person is reached by phone or by a visit at home, there are still many barriers to overcome before he or she accepts to participate. Many were suspicious of guaranteed anonymity and confidentiality: "What is the guarantee that you will not give my name to the authorities?" Some expressed feelings of resentment against Switzerland: "What's the point of that? Things will never change ... I worked all my life in Switzerland and I receive a wretched pension." Others equated the university with the authorities and feared controls: "Your questionnaire is far too intrusive." Many didn't have time for an appointment either because they were working to supplement their pension or because of travel between their country of origin and Switzerland: "I don't have time, I'm about to go back to Portugal for three months." Finally, the length and difficulty of the questionnaire scared many people. Its complexity led to the fear of not being able to correctly answer or understand the questions despite the translation. Clearly, a lower level of education compared to the overall population or cases of illiteracy may contribute to reluctance to answer a long questionnaire. For some, especially people from former Yugoslavia, reviewing their 
life course using the life event calendar involved remembering traumatizing events related to war or dictatorship. Some family members of respondents reproached this intrusiveness: "My father has had nightmares since the visit of your interviewer."

To conclude this section, VLV monitoring shows that there are specific reasons for elderly migrants to not participate in the VLV survey and that these reasons are strongly related to their living conditions and past lives. Traveling between countries of origin and Switzerland, high suspicion toward VLV, and resentment against what reminded them about the difficulties of their past life created risks of not gaining access to elderly migrants that were largely underestimated by the VLV team. The response rate was lower than for the oversamples than for the main sample, and it was hard to reach such a level. After a few weeks of fieldwork, elements of vulnerability appeared to be so prominent for elderly migrants that they started compromising the success of the VLV subproject on migration. It became urgent to start thinking about a different approach for dealing with these difficulties.

\section{Adapting the Research Design to Reduce Social Distance}

Our analyses of reasons for non-response reflects the social distance between the VLV research design and the population covered by the survey. Social distance refers to the idea of a social space structured by characteristics such as age, gender, origin, or social status (Bonnet 2008). In this sense, the survey reveals social disparity each time that the respondents have a status, in particular social status, lower than the interviewer. The survey also constitutes a space of "symbolic violence" when the interviewer or researchers unilaterally impose the rules of the gamegoals and use of data-without possible negotiation or complete understanding from the respondents (Bourdieu and Balazs 1993). Elderly migrants did not tend to identify themselves with the goals of the VLV survey; or more explicitly, we did not succeed in convincing them to. In other words, VLV remained an institutional project far from their interests. Once this was recognised, the goal of the VLV team became to reduce this social distance by innovating with the contact and interviewing procedures, but we also had to give up some goals.

Since the oversamples of the elderly coming from Portugal and Spain living in Geneva were the first to be contacted, they were used for innovating new contact and interviewing approaches and to create good practice exchanges with the VLV team in Basel. People from former Yugoslavia living in Basel were reluctant to participate, and completed interviews were rare. Considering the difficulties related to translations and interviewer recruitment, but also more importantly, the reasons of refusal that included war trauma, the VLV team decided maximizing their response rates should not be done at the expense of ethical considerations and ended this fieldwork. It was replaced by an Italian oversample in Geneva, since Italians represent $40 \%$ of immigrants 65 and over. Since Portuguese, Spanish, and Italian oversamples knew difficulties, but not to the same degree as former Yugoslavians, the VLV team decided to overcome the obstacles by respecting ethical and scientific requirements. 
The first step for these oversamples was to change the interviewers' profile to reduce social distance between interviewers and respondents. At the beginning, being bilingual was the only criterion for recruitment. A preference was given to second-generation immigrants originating from the same country as the target population and to people with a university degree. To break the deadlock, being a first-generation immigrant from the same country-or even better the same region-as the target populations, having a good network within the immigrants' communities, not necessarily having an academic profile but an experience with the elderly were the new recruitment criteria. Most of the interviewers with the previous profile were discouraged and gave up. The VLV team assigned new cases to the most effective interviewers. Interviewers with the new profile had 1 month to convince new respondents. New interviewers worked in close collaboration with the field officer to ensure quality but also to maintain their motivation. It had also been decided to not self-administer questionnaires but that the interviewers would be ready to do the entire VLV questionnaires with the respondents to prevent the obstacle of complete or partial illiteracy.

Despite the new criteria, three out of seven interviewers did not obtain an acceptable response rate. Beyond personal reasons for not fulfilling the requirements, a high level of motivation seems to be the primary factor in a high contact rate (tenacity despite the difficulty in reaching the respondents) and a low refusal rate (capacity to convince and inspire confidence):

\begin{abstract}
It was mainly to make a step towards my community, which I do not frequent a lot. It was a way to meet people and see the problems they face ... see how people cope with their living conditions. I thought it was good for them and so I was motivated to convince them of the value of the survey. I knew that, once we met, it was always a nice encounter. And I could also somehow bring a little more, give some information, the address of an association or other social information. (148, Portuguese interviewer)

I work alongside my studies. I did it for this reason. I was interested. It was an interdisciplinary survey; it ties into my studies, even a lot. Then I realized it was really interesting for them [the Spanish elders] actually. For the community. And it inspired me a lot, not only to earn one's living. (159, Spanish Interviewer)
\end{abstract}

Adding a snowball sample to the oversample was an added measure to increase the number of cases available for analysis. Respondents had to be between 65 and 79 with Spanish or Portuguese nationalities. Since it was difficult to reach these populations, the VLV team decided to include people with dual nationality. The total sample (original oversample and snowball sample) was stratified by sex. Respondents were recruited among interviewers' networks, immigrant associations, and Spanish and Portuguese churches. Each respondent was asked if he or she knew someone interested in completing the questionnaires. Since it was also hard to reach Italians, the VLV team conducted the same snowball procedure for them.

Some $13.8 \%$ (18 out of 130 individuals) of Iberian interviews come from the snowball procedure, which only had a small effect on the number of individuals from Spain in the final sample. The competence of the new Iberian interviewers to convince respondents on the phone played a more important role in explaining the 
increase in response rate. A snowball procedure through the respondents' network did not work because of the length and the content of the questionnaires:

Some people who completed the questionnaires told others what it was really about, the questions and so on, and then some refused, three-quarters of people refused because they had heard how it is ... They heard that we wanted to know about their possessions in their origin country. They wondered if their children would get in trouble because of that (156, Portuguese interviewer).

In Geneva, the number of snowball questionnaires accounted for $36.4 \%$ (43 out of 118 individuals) of the final Italian sample of respondents. As noted above, this fieldwork was launched at the end of the Iberian oversample to compensate for the failure of the ex-Yugoslavian effort. Recruitment of interviewers for the Italian oversample was based on the same procedures and profiles as for the new Iberian generation of interviewers. Five Italian collaborators started to recruit respondents from the original contact list. They also had 1 month to show their ability to convince and complete interviews. Even within this short period, contacts were decreasing too quickly. Recruitment by snowball was quickly launched.

Interviewers frequently reported difficulties for elderly migrants to be tested on cognitive resources. The latter started with a vocabulary test in French (for Geneva) and German (for Basel) that had not been translated because of equivalence problems. This test requires an excellent knowledge of vocabulary. Some respondents had a feeling of failure and were highly frustrated after this section of the questionnaire. They felt like they were being tested on their ability to speak the local language, at the same time as most of them were responding in their mother tongue to the questionnaires. This may also mirror some discussions on local language exams to test one's integration in Switzerland. Whatever the cause, it was embarrassing for the interviewers who reported people crying or furious, interrupting the procedure and refusing to continue with the survey, or staying passive until the end of the interview. The VLV team decided to give up this section for the Portuguese and Spanish respondents to prevent a break in the snowball sampling, and to not show disrespect toward the respondents.

At the end of a complicated and difficult experience, it was confirmed that reducing the social distance between research designers, interviewers, and potential respondents helped to include elderly migrants in the survey, though with varying success depending on the adaptations and the targeted populations. The question remains as to what kind of sample we get at the end of such a process.

\section{Cost-Benefit Analysis of Adapting Standard Procedures to Represent Elderly Migrants}

Adapting procedures may improve access to hard-to-reach groups within largescale surveys, but the impact of such adjustments may not be neutral regarding the quality of final samples. In the case of including elderly migrants within VLV, such 
adaptations were crucial to avoid the failure of the subproject on migration, but this also involved taking some risks. The challenge was to negotiate a trade-off between biasing results by modifying contact and interviewing procedures, and not getting a final sample large enough for further analyses. To know if the rewards made the effort worthwhile, a cost-benefit analysis of the impacts of such adjustments was necessary.

The most obvious cost is the loss of comparison with former Yugoslavians because of ending the fieldwork in Basel. This comparison was worthwhile because of the specific characteristics of this group. Their arrival in Switzerland was more recent than Italians and Spanish. Some former Yugoslavians came to Switzerland to seek asylum, which is not the case for the other groups of old immigrants who arrived as adults and grew old in Switzerland. They are not EU citizens and this difference in legal status may give rise to different practices compared to other elderly migrants such as not spending extended periods of time alternately in Switzerland and the country of origin. One of the good practices in surveys is to maximize cooperation or response rates within the limits of ethical treatment of human subjects. This last criterion played a major role for former Yugoslavians regarding the above-mentioned trade-off.

On the other hand, such a loss was compensated by an oversample of Italians in Geneva. Having Italian oversamples in Geneva and Basel allows comparison of immigrants from the same origin but who immigrated to different regions of Switzerland, which differ in their population composition, linguistic dimension, size of urban area, and integration policies. Such comparisons should give rise to analysis of the impact of these differences on immigrant living conditions at retirement.

Even if the response rate of elderly people with foreign origins remains lower than that of the main sample (see Table 2), increase in participation to the survey was an important benefit of the adjustments to the standard procedures, especially with the recruitment of new interviewers. This benefit can only be measured for the Portuguese and Spanish fieldwork because they were the first two populations for which innovating contact and interviewing procedures were introduced after having noted the difficulties of the standard procedures for these groups. Indeed, only these two projects allow a comparison between first and second wave interviewers. The following graph shows the coincidence between the increase in the response rate for the Spanish and Portuguese oversamples and the recruitment of new collaborators (Fig. 2).

It is not possible to run the same analysis to observe the effect of new recruitment for the Italian oversamples in Basel and Geneva, since they immediately benefited from the experience acquired. Nevertheless, Italian oversamples also strongly profited from the snowball approach. Indeed, $55.1 \%$ (43 out of 78 individuals) of the Italian oversample in Geneva came from the snowball approach, $54.5 \%$ (55 out of 101 individuals) in Basel. Adjusting VLV contact procedures by introducing this technique based on a positive appreciation of the social relations within the communities contributed to more than half of the final Italian oversamples.

The reader will have noticed that the initial objective of 120 respondents by nationality and canton was not achieved despite the implementation of new contact 


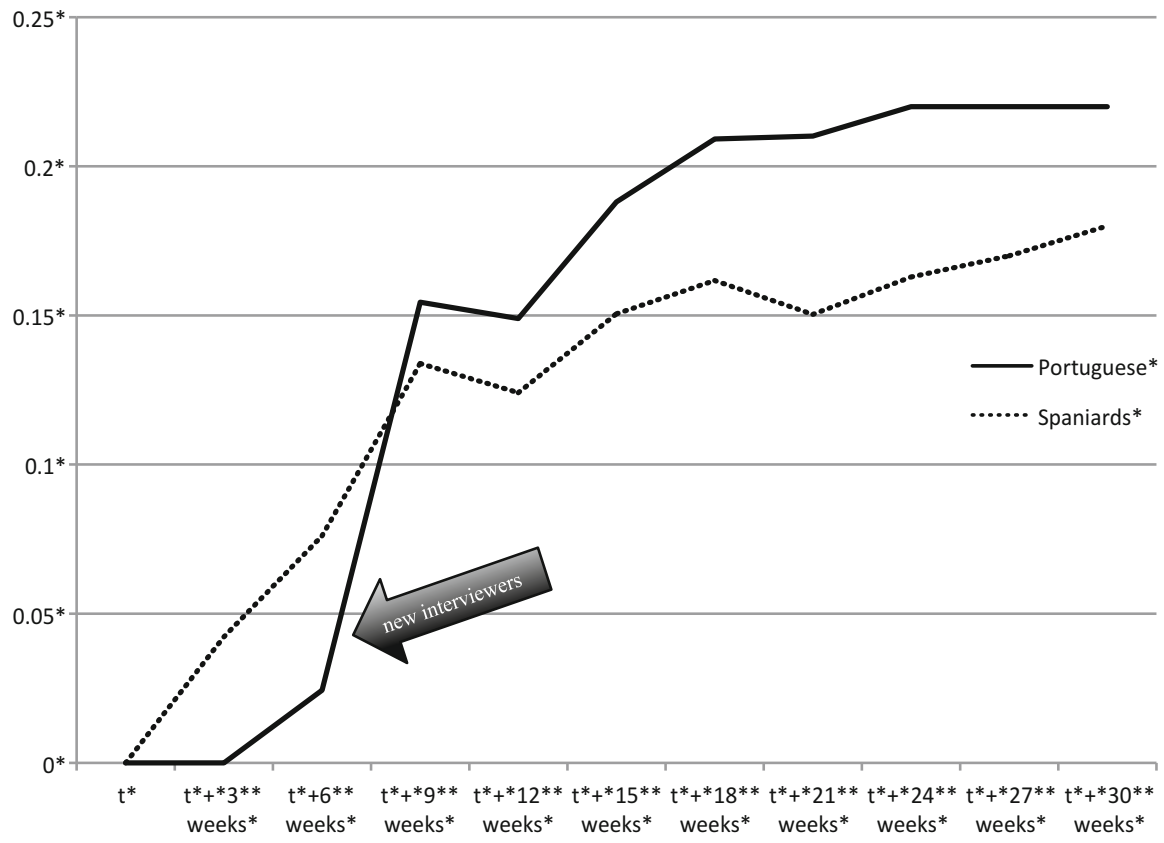

Fig. 2 Evolution of the response rate throughout fieldwork. Spanish and Portuguese oversampleGeneva-snowball sample not included

and interviewing procedures. The decision was made to take into consideration elderly migrants from the main sample as well, meaning elderly of foreign origins who were randomly selected to be part of the main fieldwork in Geneva and Basel (see Oris et al. in this volume). From a quantitative perspective, the final samples of elderly migrants are the result of several methodological choices that led to the sample composition showed in Table 3. The objective of 120 respondents by nationality and canton was achieved for Italians, but not for Portuguese and Spanish. Some researchers proposed to merge these two groups into a single Iberian sample. Nevertheless, from a theoretical point of view, this is not pertinent considering their different migratory trajectories, the evolution of migratory and integration policies, and living conditions in their host countries. In the end, the final overall immigrant sample contains 366 individuals from Italy, Spain, and Portugal between 65 and 79 .

Considering the various components of the final oversamples, one may question the impact of the different contact procedures (snowball or random sample) on the representativeness of the files delivered to the researchers. Do the respondents obtained by snowball significantly differ from those randomly obtained? This question is not relevant for the Portuguese oversample since only two participants were part of the snowball sample, however, a significant share of the Spanish and Italians were recruited through this procedure. To establish if those two subpopulations significantly differ from each other, we ran chi-square tests (or 
Table 3 Composition of the VLV final samples of elderly migrants

\begin{tabular}{|c|c|c|c|c|c|}
\hline & \multicolumn{3}{|c|}{ Geneva } & \multirow{2}{*}{$\begin{array}{l}\text { Basel } \\
\text { Italy }\end{array}$} \\
\hline & & Italy & Portugal & Spain & \\
\hline \multirow[t]{4}{*}{ Oversample } & \multirow[t]{2}{*}{ Random } & 35 & 61 & 41 & 46 \\
\hline & & $30 \%$ & $97 \%$ & $61 \%$ & $39 \%$ \\
\hline & \multirow[t]{2}{*}{ Snowball } & 43 & 2 & 16 & 55 \\
\hline & & $36 \%$ & $3 \%$ & $24 \%$ & $47 \%$ \\
\hline \multirow{2}{*}{\multicolumn{2}{|c|}{ Main sample }} & 40 & 0 & 10 & 17 \\
\hline & & $34 \%$ & $0 \%$ & $15 \%$ & $14 \%$ \\
\hline & Total & 118 & 63 & 67 & 118 \\
\hline
\end{tabular}

Fisher's exact test in the case of small $\mathrm{n}$ in the cross-tables) to test the null hypothesis of no significant association between the age group, sex, level of education, and last occupational status of respondents and the method of sampling (random/snowball). The p-values of each test are above 0.05 , so we accept the null hypothesis and conclude that there is no significant bias as far as the above-mentioned variables are concerned. To conclude, the adjustments of contact approaches do not appear to have distorted the quality of the final samples and allow a sample large enough to run some descriptive and multivariate analyses.

The initial objective was reached since elderly migrants are largely overrepresented in the VLV database. For example, Spanish migrants are three times more numerous in our database (for the 65-79 year-olds) than they are in the residential population. Consequently, weighting issues do arise, and attention should be paid as to how weights are assigned. Furthermore, manipulating the database with care remains crucial considering the impossibility to reach many of them. When analyzing and interpreting the data, one has to be conscious of what the database contains and what it does not. The file does not include individuals who left Switzerland to spend their retirement in their country of origin (though it was not the goal of VLV to gain access to such groups), individuals who did not identify themselves to the goals and uses of VLV, and individuals who were not in Switzerland at the time of the survey. Moreover, with such complicated questionnaires, the biggest risk for VLV was to reach only highly skilled persons who are the exceptions among elderly migrants from Italy, Spain, and Portugal living in Switzerland. Nevertheless, the focus group with the interviewers in charge of the oversamples demonstrates that the risk did not materialize for VLV:

I had many respondents who only did primary school, or almost nothing. Because at that time it was normal, education was not mandatory in Spain, in Franco's time ... A lot dropped out of school to help their family or to help in the fields ... For illiterate respondents, it was not a big deal for us because we were with them all the time throughout the questionnaire, we were there for that purpose, and then it was easy. (159, Spanish interviewer).

Further analysis on socioeconomic and health conditions confirm these words: elderly migrants in the VLV database generally have a low level of education, a low 
skilled status, and suffer from worse health status and economic situations than the overall population of the same age (Kaeser and Bolzman 2013).

\section{Capturing Vulnerability: A Delicate Balance Between Scientific Requirements and Realities on the Ground}

The VLV experience underlines the dilemma of large-scale surveys aimed at capturing vulnerability: not having tailored contact and interviewing procedures but running the risk of failing to capture vulnerability; or introducing specific procedures but running the risk of impairing the comparison. VLV's team faced this tension through an active dialogue between scientific requirements and realities on the ground to adapt survey procedures pragmatically and carefully.

To create conditions that favor such a dialogue, it is first necessary to take into account the components and reasons why target groups might be vulnerable. It is fundamental to get to know as much as possible about the groups' specificities before launching the fieldwork, and to create contact and interviewing procedures in accordance with the different components of the target groups. Most important, it is crucial to take time throughout the fieldwork to establish and maintain a pragmatic dialogue within the research team to understand what happened on the ground and to respect scientific requirements of research designers at the same time. Such a balance is key to reducing social distance between research designers, interviewers and respondents, and to assessing vulnerability without impairing the quality of the data.

As we have seen, social distance between the target populations and the survey may be expressed through age, socioeconomic status, social and cultural capital, and other factors. It may lead to an asymmetric relation between the interviewersrepresenting the monopole of symbolic violence brought about by the formality of the survey - and the respondents. The VLV experience confirms that the interviewers play a major role in reducing this gap. They are more than a neutral conduit for the transmission of standardized questionnaires. They constitute intermediaries because of their "double affiliations to the world of researchers and to the world of respondents"5 (Bessière and Houseaux 1997: 103). When they are aware, they can manage the intrinsic ambivalence of the survey situation to produce more positive and fewer negative outcomes. This is a reminder that research designers need to communicate, train, manage, and inform interviewers not only before but also throughout the fieldwork according to the goals and uses of the survey to create reflexivity from the collaborators on their practices and roles.

Admittedly, the price may be a time- and money-consuming survey, the necessity to be flexible, getting off the beaten track, and even sometimes giving up some comparisons as was the case for the VLV's cognitive tests. Nevertheless, this is

\footnotetext{
${ }^{5}$ Author's own translation.
} 
often necessary if one claims to better understand vulnerability. Not taking this major issue into account means running the risk of getting into a vicious circle: being vulnerable puts oneself at risk of not being reached by a large-scale survey, and not being represented in large-scale surveys may amount to being ignored by scientific and political agendas. Providing resources to assess vulnerability is not only a methodological engagement; this is also a major social issue about giving a voice to the voiceless.

Acknowledgements This communication results from research works executed within the framework of the National Centre of Competence in Research LIVES and the SINERGIA Project CRSII1-129922, which are financed by the Swiss National Science Foundation. The author is grateful to the Swiss National Science Foundation for its support. The author is warmly thankful to Prof. Michel Oris for his significant support and contribution during the data collection and for having carefully reviewed this chapter, and to Dr. Floriane Demont and Dr. Guy Elcheroth for their scientific support during the writing process. Finally, the author thanks the interviewersespecially the ones in charge of the elderly migrants' sample-and the staff of the centre for the interdisciplinary study of gerontology and vulnerability who highly contributed to the VLV data collection.

Open Access This chapter is licensed under the terms of the Creative Commons AttributionNonCommercial 2.5 International License (http://creativecommons.org/licenses/by-nc/2.5/), which permits any noncommercial use, sharing, adaptation, distribution and reproduction in any medium or format, as long as you give appropriate credit to the original author(s) and the source, provide a link to the Creative Commons license and indicate if changes were made.

The images or other third party material in this chapter are included in the chapter's Creative Commons license, unless indicated otherwise in a credit line to the material. If material is not included in the chapter's Creative Commons license and your intended use is not permitted by statutory regulation or exceeds the permitted use, you will need to obtain permission directly from the copyright holder.

\section{References}

Bessière, C., \& Houseaux, F. (1997). Suivre des enquêteurs. Genèses, 29, 100-114.

Bolzman, C., Fibbi, R., \& Vial, M. (2001). Les loisirs des personnes âgées immigrées: pratiques, besoins, demandes. Genève: Institut d'études sociales.

Bolzman, C., Poncioni, R., Vial, M., \& Fibbi, R. (2004). Older labour migrants' wellbeing in Europe: The case of Switzerland. Ageing and Society, 24(3), 411-429.

Bonnet, F. (2008). La distance sociale dans le travail de terrain: compétence stratégique et compétence culturelle dans l'interaction d'enquête. Genèses, 4(73), 57-74.

Bourdieu, P., \& Balazs, G. (1993). L'interrogatoire. In P. Bourdieu (Ed.), La Misère du monde (pp. 927-939). Paris: Éditions du Seuil.

Elcheroth, G., Fasel, N., Gianettoni, L., Kleiner, B., Laganà, F., Lipps, F., Penic, S., \& Pollien A. (2011, September). Minorities in general social surveys: What we can learn from the Swiss case and why the black box should be opened wider. FORS Position Paper Series.

Feskens, R., Hox, J., Lensvelt-Mulders, G., \& Schmeets, H. (2006). Collecting data among ethnic minorities in an international perspective. Field Methods, 18(3), 284-304. 
Gerville-Réache, L., Couallier, V., \& Paris, N. (2011). Echantillon représentatif (d'une population finie): Définition statistique et propriétés. Archive ouverte pluridisciplinaire $H A L, \mathrm{n}^{\circ}$ hal00655566.

Groves, R. (2006). Nonresponse rates and nonresponse bias in household surveys. Public Opinion Quarterly, 70(5), 646-675.

Groves, R. M., \& Couper, M. P. (1998). Nonresponse in household interview surveys. New York: Wiley.

Guichard, E., Nicolet, M., Monnot, C., Joye, D., \& Oris, M. (2012). Surveying the elderly in Switzerland. Conference organized by the NCCR-LIVES, Lausanne.

Harckness, J. (2003). Questionnaire translation. In J. A. Harkness, F. J. R. Van de Vijver, \& P. P. Mohler (Eds.), Cross-cultural survey methods (pp. 35-56). Hoboken: Wiley-Interscience.

Kaeser, L., \& Bolzman, C. (2013). The well-being of immigrant elders. Conference organized by the Research Committee on Migration of the International Sociological Association, Tel-Aviv.

Laganà, F., Elcheroth, G., Penic, S., Kleiner, B., \& Falsel, N. (2011). National minorities and their representation in Swiss surveys (II): Which practices make a difference? (FORS working paper series, paper 2011-3). Lausanne: FORS.

Laganà, F., Elcheroth, G., Penic, S., Kleiner, B., \& Fasel, N. (2013). National minorities and their representation in Swiss surveys (II): Which practices make a difference? Quality and Quantity, 47(3), 1287-1314.

Lalive d'Epinay, C., Bickel, J. F., Maystre, C., \& Vollenwyder, N. (2000). Vieillesses au fil du temps. 1979-1994: Une révolution tranquille. Lausanne: Réalités sociales.

Lipps, O., Laganà, F., Pollien A., \& Gianettoni L. (2011). National minorities and their representation in Swiss surveys (I): Providing evidence and analyzing causes for their underrepresentation, FORS Working Paper, (2), 1-20.

Ludwig, C., Cavalli, S., \& Oris, M. (2014). "Vivre/Leben/Vivere": An interdisciplinary survey addressing progress and inequalities of aging over the past 30 years in Switzerland. Archives of Gerontology and Geriatrics, 58(2), 240-248.

Marpsat, M., \& Razafindratsima, N. (2010). Les méthodes d'enquêtes auprès des populations difficiles à joindre: introduction au numéro spécial. Methodological Innovations Online, 5(2), $3-16$.

Mauger, G. (1991). Enquêter en milieu populaire. Genèses, 6, 125-142.

Piguet, E. (2004). L'immigration en Suisse. Cinquante ans d'entrouverture. Lausanne: Presses polytechniques et universitaires romandes.

Riandey, B., \& Quaglia, M. (2009). Surveying hard-to-reach groups. In P. Bonnel, M. LeeGosselin, J. Zmud, \& J. L. Madre (Eds.), Transport survey methods: Keeping up with a changing world (pp. 127-144). Bingley: Emerald.

Rossini, S. (2013). De la mesure des politiques sociales. In J. M. Bonvin, P. Gobet, S. Rossini, \& J. P. Tabin (Eds.), Manuel de politiques sociales (pp. 91-117). Lausanne: EESP et Réalités sociales.

Schiltz, M. A. (2005). Faire et défaire des groupes: L'information chiffrée sur les "populations difficiles à atteindre". Bulletin of Sociological Methodology, 86, 30-54.

Spini, D., Hanappi, D., Bernardi, L., Oris, M., \& Bickel, J. F. (2013). Vulnerability across the life course: A theoretical framework and research directions. LIVES Working Paper, 2013 (27).

Tabutin, D. (2006). Les systèmes de collecte des données en démographie. In G. Caselli, J. Vallin, \& G. Wunsch (Eds.), Démographie, analyse et synthèse. Vol. VIII. Observation, méthodes auxiliaires, enseignement et recherche (pp. 13-64). Paris: National Institute of Demographic Study.

Von dem Knesebeck, O., Wahrendorf, M., Hyde, M., \& Siegrist, J. (2007). Socioeconomic position and quality of life among older people in 10 European countries: Results of the SHARE study. Ageing and Society, 27(2), 269-284. 